\title{
Studies on the Oxidation of Myricetin Glycosides by Tea Oxidase
}

\author{
Formation of $2^{\prime}, 2^{\prime \prime \prime}$-Biflavonol, a New Biflavonoid
}

Sir:

Myricetin glycosides ${ }^{1)}$ in fresh tea leaves decrease markedly during the fermentation process of manufacturing black tea. This fact suggests that they may be oxidized by the action of the tea oxidase. In order to elucidate the mechanism of this reaction, enzymic oxidation in vitro was carried out, using myricitrin as the substrate and the insoluble fraction of minced tea leaves as enzyme preparation. Myricitrin alone was not oxidized by the tea oxidase, but the addition of a substance containing o-dihydroxyphenol group, such as $d$-catechin or catechol, caused rapid oxidation of myricitrin. By extraction of the reaction mixture with $n$-butanol and fractionation with silica gel column, four products $\left(G_{1}, G_{2}, G_{3}\right.$ and $\left.G_{4}\right)$ were obtained in crystals.

As the substance $G_{3}$, one of the main products, was obtained in the largest quantity, the elucidation of its construction was tried first of all. Yield: $2.5 \mathrm{~g}$ from $30 \mathrm{~g}$ of myricitrin. Yellow needles (recrystallized from water), m.p. $215^{\circ} \mathrm{C}$ (decomp.) . Anal. Found: C, 54.38; $\mathrm{H}$, 4.34. Calcd. for $\mathrm{C}_{42} \mathrm{H}_{38} \mathrm{O}_{24}$, assuming $\mathrm{G}_{3}$ to be a dimer of myricitrin: $\mathrm{C}$, 54.43; H, $4.10 \%$. Hydrolysis with $5 \%$ sulfuric acid yielded the aglycone in yellow needles (water), m.p. $246^{\circ} \mathrm{C}$ (decomp.). Anal. Found: C, 56.73; H, 3.23. Calcd. for $\mathrm{C}_{30} \mathrm{H}_{18} \mathrm{O}_{16}$ : C, 56.78; H, 2.84\%. Dodecaacetate, m.p. $270^{\circ}$ C. Anal. Found: C, 56.92; $\mathrm{H}, 3.86 ; \mathrm{CH}_{3} \mathrm{CO}$, 45.38. Calcd. for $\mathrm{C}_{54} \mathrm{H}_{42} \mathrm{O}_{28}$ :

\footnotetext{
1) Y. Takino, H. Imagawa and H. Yoshida, This Journal, to be published.
}

C, 56.94; H, 3.69; $\mathrm{CH}_{3} \mathrm{CO}, 45.34 \%$. Rhamnose was detected in the filtrate.

On the other hand, it was found that the same substance as $\mathbf{G}_{3}$-aglycone can be obtained in a large amount by oxidation of myricitrin with potassium ferricyanide, without laborious procedure of fractionation. The identity of the substance with $\mathrm{G}_{3}$-aglycone was ascertained by the comparison of their melting point, UV-, IR-spectra and other properties. Therefore the further study has been continued on this substance. The methylation with diazomethane produced colorless prismatic crystals (ethanol), m.p. $229^{\circ}$ C. Anal. Found: C, 62.85; H, 5.18. Calcd. for $\mathrm{C}_{42} \mathrm{H}_{42} \mathrm{O}_{16}: \mathrm{C}, 62.84 ; \mathrm{H}, 5.24 \%$. When treated with $20 \%$ alcoholic potassium hydroxide, the methylated aglycone gave $o$-hydroxyfisetol trimethyl ether (I) and 4, $4^{\prime}, 5,5^{\prime}, 6,6^{\prime}$-hexamethoxydiphenic acid (II) . I: colorless prismatic crystals (ethanol), m.p. $103^{\circ} \mathrm{C}$. Mixed with an authentic specimen prepared from myricetin hexamethyl ether according to the method of A. G. Perkin ${ }^{2)}$, I showed no depression of melting point. Anal. Found: $\mathrm{C}_{\text {, }}$ 58.76; H, 6.33. Calcd. for $\mathrm{C}_{11} \mathrm{H}_{14} \mathrm{O}_{5}$ : $\mathrm{C}, 58.41$; $\mathrm{H}, 6.19 \%$. II: colorless prismatic crystals (ethanol), m.p. $239^{\circ} \mathrm{C}$. For comparison, this compound was also prepared by hydrolyzing the methylated product of diethyl $4,4^{\prime}, 5,5^{\prime} 6,6^{\prime}-$ hexahydroxydiphenate. The mixed melting point showed no depression. Anal. Found: C, 56.77; H, 5.18. Calcd. for $\mathrm{C}_{20} \mathrm{H}_{22} \mathrm{O}_{10}$ : C, $56.87 ; \mathrm{H}, 5.21 \%$. II was also identified by the 2) A.G. Perkin, J. Chem. Soc., 99, 1721 (1911). 


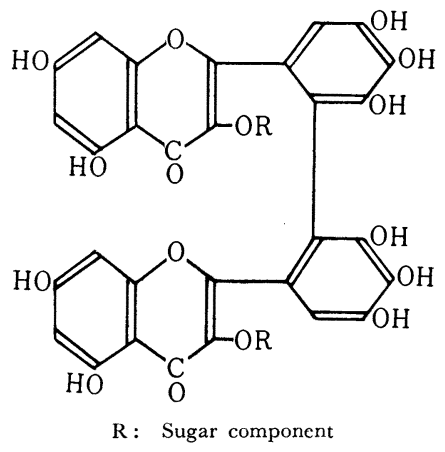

fact that it gives ellagic acid when it is demethylated with conc. hydriodic acid.

From this evidence we conclude that $G_{3}$ is

a new biflavonoid having a structure of $2^{\prime}, 2^{\prime \prime \prime}$ biflavonol, and that the myricetin glycoside is oxidized enzymatically in the presence of an $o$-dihydroxyphenol compound as a carrier or directly by oxidizing reagent, and thus forms a dimer of the biphenyl type linking at position 2' of each molecule.

Hiroshi Imagawa

Yoshinori TAKINO

Department of Agricultural

Chemistry, Faculty of Agriculture,

Tokyo University of Education,

Tokyo.

Received June 14, 1962 